\title{
Solution of Rectangular Plate on Winkler's Elastic Foundation Using Characteristic Orthogonal Polynomials
}

\author{
E. I. Ogunjiofor
}

Department of Civil Engineering, Chukwuemeka Odumegwu Ojukwu University, Uli, Anambra State, Uli, Nigeria

\begin{tabular}{ll}
\hline DOI: $10.36348 /$ sjce.2020.v04i08.001 & | Received: 30.09 .2020 | Accepted: 14.10 .2020 | Published: 18.10 .2020
\end{tabular}

*Corresponding author: Emmanuel Ifeanyi Ogunjiofor

Abstract

Plates supported on elastic foundations are found in many civil engineering applications. The analysis requires a critical understanding between the plate element and the foundation. The objective of this study is to come up with a better, simple, and easy analytical method that could be used for the analysis of all-round simply supported plate on Winkler's elastic foundation. The scope of the work includes static analysis of an isotropic simply supported rectangular plate resting on an elastic foundation carrying a uniformly distributed load. In this paper, characteristic orthogonal polynomials (COPs) shape functions for all-round simply supported rectangular plate on an elastic foundation were formulated by using Galerkin variational Energy method. The COPs shape functions formulation had been carried out by direct integration of the governing differential equation of the plate with those of elastic foundation using the Winkler model for the elastic foundation. The results obtained are very close to the results obtained by earlier research works that used different methods.

Keywords: characteristic orthogonal polynomials, Galerkin method, rectangular plate, Elastic Foundation, Winkler model.

Copyright () 2020 The Author(s): This is an open-access article distributed under the terms of the Creative Commons Attribution 4.0 International License (CC BY-NC 4.0) which permits unrestricted use, distribution, and reproduction in any medium for non-commercial use provided the original author and source are credited.

\section{INTRODUCTION}

Plates on an elastic foundation are common structural elements employed in many civil engineering applications such as foundations, storage tanks, swimming pools, floor systems of buildings and highways, airfield pavements, etc. The field of plate bending on an elastic foundation have received considerable attention due to their wide application in civil engineering. Since the interaction between structural foundations and supporting soil has great importance in many engineering applications, a considerable amount of research has been conducted to deal with bending, buckling, and vibration problems of plates. The essence is to find a convenient representation of the physical behaviour of real structural components supported on a foundation.

The usual approach in formulating problems of plates continuously supported by elastic media is based on the inclusion of the foundation reaction in the corresponding differential equation of the plate. To include the behaviour of foundation properly into the mathematical equation, it is necessary to make some assumptions. One of the most useful simplified models for soil- foundation interaction known as the Winkler model is the model assumed for this analysis. Winkler's model assumes that the foundation behaves elastically and that the vertical displacement and pressure underneath it are linearly related to each other. That is, it is assumed that the supporting medium is isotropic, homogeneous and linearly elastic, provided that the displacements are "small". This simplest simulation of an elastic foundation is considered to provide vertical reaction by a composition of closely spaced independent vertical linearly elastic springs.

Currently, most of the researchers use approximate and numerical methods to solve the governing differential equations of a plate on an elastic foundation.

Timoshenko and Woinowsky [1], used Mavier solution to solve the problem of a simply supported rectangular plate resting on elastic foundation. Karasin [2], extended exact stiffness, geometric stiffness and consistent mass matrices of Beam element on a twoparameter elastic foundation to solve plate on elastic foundation problems by finite civil solution. Ragesh [3], used the finite element method to analyse an isotropic rectangular plate by using a four noded Kirchhoff 
rectangular element with three degrees of freedom per node with the Winkler model for an elastic foundation. In his work, the finite element formulation was carried out by integrating the properties of the plate with those of elastic foundation. Zhong \& Fanjin [4], used reciprocal theorem method to obtain the theoretical solutions for a rectangular plate supported on the elastic foundation with free edges. Ling Xing and Qu Qing [5], analysed orthogonal rectangular plate with four free edges rested on an elastic foundation using General Exact Solution. These studies obtained the solution of the deflection function by simple simulation of an elastic foundation which is considered to provide vertical reaction by a composite of closely spaced independent vertical linearly elastic spring.

This study, therefore, presents the use of COPs functions in the analysis of SSSS plate on Winklers elastic foundation. The fundamental theories applied on the Winklers modal of a plate on an elastic foundation are classical plate theory (thin plates) and Galerkin's variational method.

\section{Characteristic Orthogonal Polynomials}

The Gram-Schmidt process can be used to formulate a class of COPs for SSSS plate on elastic foundation and then those polynomials are employed as deflection functions in the analysis [6]. Previously deflection functions were formulated by inspection and sometimes by trial and error until [7] proposed a systematic method of constructing such functions in the form of COP. The restrictions on the series are the following.

- They satisfied the geometrical boundary conditions.

- They are complete.

- They do not inherently violate the natural boundary conditions

When the above conditions are met, the numerical solutions converge to the exact solution and it depends also on the number of terms taken in the admissible series. Different series types, viz., trigonometric, hyperbolic, polynomial, give different results for the same number of terms in the series and the efficiency of the solution will depend to some extent on the type of series chosen [8].

Bhat [7], used the Gram-Schmidt orthogonalization method to generate the COPs for one dimension and showed that the orthogonal polynomial offered improved convergence and better results. This same principle can be applied for two-dimensional structure by assuming a function which is a product of the two independent dimensions.

Following the principle stated in [7], the displacement function for rectangular plate is therefore assumed as a product of pure functions of $\mathrm{x}$ and $\mathrm{y}$ as in Equation (1)

$$
W_{x, y}=F(x) * G(y)=\sum_{m=0}^{\infty} \sum_{n=0}^{\infty} X_{m} x^{m} Y_{n}
$$

Take, for instance, a rectangular plate of dimension "a" along the $\mathrm{x}$-axis and " $\mathrm{b}$ " by the $\mathrm{y}$-axis. If the deflection pattern of the plate along $x$ is represented by a beam strip qualitatively and the beam function is taken as $\mathrm{f}(\mathrm{x})$. Likewise, the corresponding beam function along the $y$-axis is taken as $G(y)$.

Expressing equation (1) in the form of nondimensional parameters, say $\mathrm{R}$ and $\mathrm{Q}$ for $\mathrm{x}$ and $\mathrm{y}$ directions respectively, we obtain.

$x=a R ; y=b Q$

Then Equation (1) becomes

$w(R, Q)=\sum_{m=0}^{\infty} \sum_{n=0}^{\infty} A_{m} R^{m} B_{n} Q^{n}$

Where

$A_{m}=X_{m} a^{m}$ and $B_{n}=Y_{n} b^{n}$

Recalling that the governing differential equation of plate, is a fourth-order differential equation and the density is constant, then, the value of $m$ and $n$ in equation (3) must be equal to 4 . If the variation of loading is linear or a second-degree parabola, the value of the power $m$ and $n$ will be 5 and 6 respectively and so on [9]. Therefore, for an SSSS plate on an elastic foundation subjected to a uniformly distributed load will have a fourth-order deflection function.

Expanding equation 3 to fourth order series gives

$$
W(R, Q)=\left(i_{0}+i_{1} R+i_{2} R^{2}+i_{3} R^{3}+i_{4} R^{4}\right)\left(j_{0}+j_{1} Q+j_{2} Q^{2}+j_{3} Q^{3}+j_{4} Q^{4}\right)
$$

Where,

$$
W(R)=\left(i_{0}+i_{1} R+i_{2} R^{2}+i_{3} R^{3}+i_{4} R^{4}\right)
$$

And

$$
W(Q)=\left(j_{0}+j_{1} Q+j_{2} Q^{2}+j_{3} Q^{3}+j_{4} Q^{4}\right)
$$

The coefficient $i_{m}$ and $j_{n}$ of the series are determined from the boundary conditions at the edges of the plate.

\section{Boundary Conditions}

Figure-1 shows a thin rectangular plate whose all edges $\mathrm{R}=0,1$; and $\mathrm{Q}=0,1$ are simply supported. 


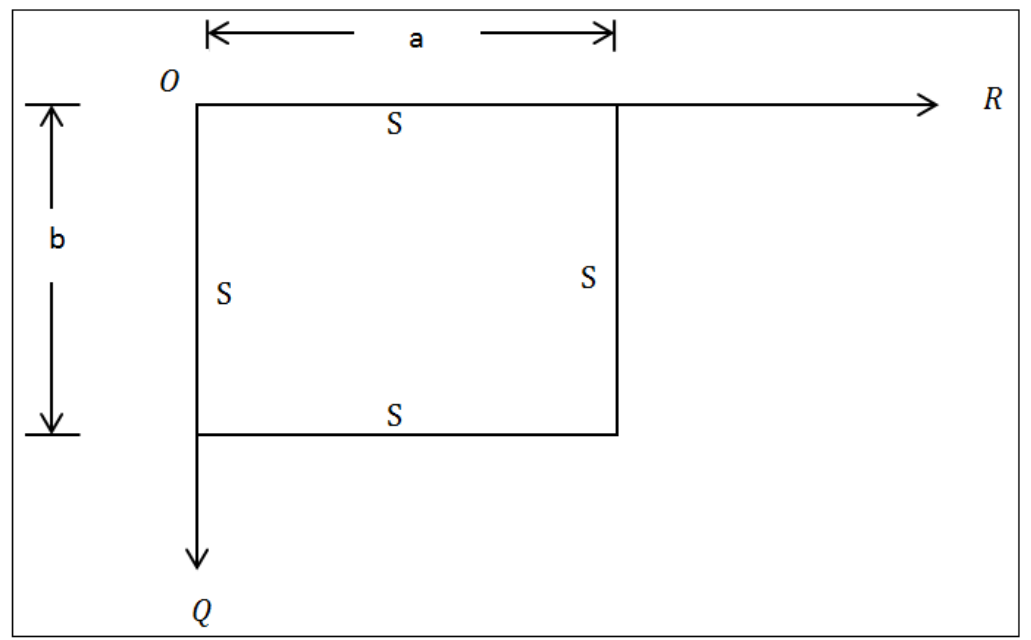

Fig-1: All Round Simply Supported Rectangular Plate (SSSS)

- Deflections at all edges are zero $\left(w_{x}=0\right.$ for $x=0,1$, and $w_{y}=0$ for $\left.y=0,1\right)$

- Moment at all edges are zero $\left(\frac{\partial^{2} w_{x}}{\partial x^{2}}=0\right.$ for $x=0,1$, and $\frac{\partial^{2} w_{y}}{\partial y^{2}}=0$ for $\left.y=0,1\right)$

For R - directions

At $R=0$, here deflection and moment are all zero, therefore we have
(i) $\mathrm{w}_{\mathrm{R}}=i_{0}=0 \therefore i_{\mathrm{o}}=0$
(ii) $\mathrm{M}_{\mathrm{R}}=0 \therefore i_{2}=0$

At $\mathrm{R}=1$, here deflection and moment are all zero, therefore we have (iii) $\mathrm{W}_{R}=i_{3}+2 i_{4}=0$

$$
\therefore i_{3}=-2 i_{4}
$$

(iv) $\mathrm{M}_{\mathrm{R}}=6 i_{3}+12 i_{4}=0$

$$
\therefore i_{1}=i_{4}
$$

Substituting the value of $i_{0}, i_{1}, i_{2}$, and $i_{3}$ into equation (6) we obtain:

$\mathrm{W}_{\mathrm{R}}=i_{4}\left(\mathrm{R}-2 \mathrm{R}^{3}+\mathrm{R}^{4}\right)$

For Q - direction

At $Q=0$, here deflection and moment are all zero, therefore we have
(i) $\mathrm{w}_{\mathrm{Q}}=j_{0}=0 \therefore j_{\mathrm{o}}=0$
(ii) $\mathrm{M}_{\mathrm{Q}}=0 \quad \therefore j_{2}=0$

At $Q=1$, here deflection and moment are all zero, therefore we have

$$
\begin{aligned}
& \text { (iii) } \mathrm{W}_{Q}=j_{3}+2 j_{4}=0 \therefore j_{3}=-2 j_{4} \\
& \text { (iv) } \mathrm{M}_{Q}=6 j_{3}+12 j_{4}=0 \therefore j_{1}=j_{4}
\end{aligned}
$$

Substituting the value of $j_{0}, j_{1}, j_{2}$, and $j_{3}$ into 3.40 we obtain:

$$
\mathrm{W}_{\mathrm{Q}}=j_{4}\left(\mathrm{Q}-2 \mathrm{Q}^{3}+\mathrm{Q}^{4}\right)
$$

Substituting Equations (12) and (17) into Equation (5), we will obtain the displacement function for an all-round simply supported rectangular plate on elastic foundation as;

$$
\mathrm{W}(\mathrm{R}, \mathrm{Q})=\wedge i_{4} j_{4}\left(\mathrm{R}-2 \mathrm{R}^{3}+\mathrm{R}^{4}\right)\left(Q-2 Q^{3}+Q^{4}\right)
$$

Let the product constants $\wedge i_{4} j_{4}$ be given as $W_{u v}$

$$
W_{u v}=\wedge i_{4} j_{4}
$$


Where $W_{u v}$ is the deflection function and $\Lambda$ is the consolidated coefficient of deflection Therefore the deflection is given as

$W(R, Q)=W_{u v}\left(R-2 R^{3}+R^{4}\right)\left(Q-2 Q^{3}+Q^{4}\right)$

Formulation of Characteristic Orthogonal Polynomials (COPs) shape functions by Energy method (based on Galerkin's method)

The equilibrium equation of rectangular plate on Winklers elastic foundation is given as

$$
\begin{aligned}
& \frac{\partial^{4} w}{\partial x^{4}}+2 \frac{\partial^{4} w}{\partial x^{2} \partial y^{2}}+\frac{\partial^{4} w}{\partial y^{4}}+\frac{k w}{D}-\frac{q}{D}=0 \\
& D=\frac{E h^{3}}{12\left(-\mu^{2}\right)} \ldots \ldots \ldots \ldots \ldots \ldots \ldots \ldots \ldots \ldots \ldots \ldots \ldots \ldots
\end{aligned}
$$

Where,

$w(x, y)$ is an unknown deflection function of $\mathrm{x}$ and $\mathrm{y}$ variables, $\mathrm{q}$ is the applied load,

$\mathrm{k}$ is the share grade of the soil, $\mathrm{D}$ is the modulus of rigidity of the plate, $\mathrm{E}$ is the young modulus of elasticity, $\mathrm{h}$ is the thickness of the plate, $\mu$ is the Poisson's ration of the plate

Applying the Galerkin's Energy approach according to Ibearugbulem, Ezeh and Ettu [10], on Equation (21), we have

$$
\int_{0}^{1} \int_{0}^{1}\left(\frac{\partial^{4} w}{\partial x^{4}} \cdot w+2 \frac{\partial^{4} w}{\partial x^{2} \partial y^{2}} \cdot w+\frac{\partial^{4} w}{\partial y^{4}} \cdot w\right) d y d x+\frac{k}{D} \int_{0}^{1} \int_{0}^{1} w \cdot w d y d x-\frac{q}{D} \int_{0}^{1} \int_{0}^{1} w d y d x=0
$$

Substituting $x=a R$ and $y=b Q$ into eqation (23)gives

$$
\int_{0}^{1} \int_{0}^{1}\left(\frac{1}{a^{4}} \frac{\partial^{4} w}{\partial R^{4}} \cdot w+2 \frac{1}{a^{2} b^{2}} \frac{\partial^{4} w}{\partial R^{2} \partial Q^{2}} \cdot w+\frac{1}{b^{4}} \frac{\partial^{4} w}{\partial Q^{4}} \cdot w+\frac{k w^{2}}{D}\right) \partial R \partial Q-a b \frac{q}{D} \int_{0}^{1} \int_{0}^{1} w \partial R \partial Q=0
$$

Where,

$$
\begin{aligned}
& w * \frac{\partial^{4} w}{\partial R^{4}}=24 W_{u v}^{2}\left(R-2 R^{3}+R^{4}\right)\left(Q^{2}-4 Q^{4}+2 Q^{5}+4 Q^{6}-4 Q^{7}+Q^{8}\right) \\
& w * \frac{\partial^{4} w}{\partial Q^{4}}=24 W_{u v}^{2}\left(Q-2 Q^{3}+Q^{4}\right)\left(R^{2}-4 R^{4}+2 R^{5}+4 R^{6}-4 R^{7}+R^{8}\right) \\
& w^{2}=W_{u v}^{2}\left[\left(R^{2}-4 R^{4}+2 R^{5}+4 R^{6}-4 R^{7}+R^{8}\right)\left(Q^{2}-4 Q^{4}+2 Q^{5}+4 Q^{6}-4 Q^{7}+Q^{8}\right)\right] \\
& \frac{\partial^{4} w}{\partial R^{2} \partial Q^{2}} * w=W_{u v}^{2}\left[( 1 - 1 2 R ^ { 2 } + 8 R ^ { 3 } + 3 6 R ^ { 4 } - 4 8 R ^ { 5 } + 1 6 R ^ { 6 } ) \left(1-12 Q^{2}+8 Q^{3}+36 Q^{4}-48 Q^{5}+\right.\right. \\
& \left.16 Q^{6}\right] \partial R \partial Q
\end{aligned}
$$

Thus, substituting the derivatives of Equation (24) with the values in Equation (25) through Equation (28) gives

$$
\begin{aligned}
& \int_{0}^{1} \int_{0}^{1}\left(\frac{1}{a^{4}}\left(24 W_{u v}^{2}\left(R-2 R^{3}+R^{4}\right)\left(Q^{2}-4 Q^{4}+2 Q^{5}+4 Q^{6}-4 Q^{7}+Q^{8}\right)\right)+2 \frac{1}{a^{2} b^{2}}\left(W _ { u v } ^ { 2 } \left[\left(1-12 R^{2}+8 R^{3}+\right.\right.\right.\right. \\
& \left.\left.36 R^{4}-48 R^{5}+16 R^{6}\right) *\left(1-12 Q^{2}+8 Q^{3}+36 Q^{4}-48 Q^{5}+16 Q^{6}\right] \partial R \partial Q\right)+\frac{1}{b^{4}}\left(2 4 W _ { u v } ^ { 2 } \left(Q-2 Q^{3}+\right.\right. \\
& \left.\left.Q^{4}\right)\left(R^{2}-4 R^{4}+2 R^{5}+4 R^{6}-4 R^{7}+R^{8}\right)\right)+ \\
& \left.\frac{k\left(W_{u v}^{2}\left[\left(R^{2}-4 R^{4}+2 R^{5}+4 R^{6}-4 R^{7}+R^{8}\right) *\left(Q^{2}-4 Q^{4}+2 Q^{5}+4 Q^{6}-4 Q^{7}+Q^{8}\right)\right]\right)}{D}\right) \partial R \partial Q-a b \frac{q}{D} \int_{0}^{1} \int_{0}^{1}\left(w_{u v}\left(R-2 R^{3}+R^{4}\right)(Q-\right. \\
& \left.\left.2 Q^{3}+Q^{4}\right)\right) \partial R \partial Q=0 \ldots \ldots \ldots \ldots \ldots \ldots \ldots \ldots . . . \ldots \ldots \ldots
\end{aligned}
$$

Substituting the deflection $w$ in Equation (23) with an assumed equation of deflection given in Equation (30), we obtain Equation (31)

$$
w=W_{u v} H
$$

Where,

$$
H=\left(R-2 R^{3}+R^{4}\right)\left(Q-2 Q^{3}+Q^{4}\right)
$$

We have

$$
W_{u v} \int_{0}^{1} \int_{0}^{1}\left(\frac{1}{a^{4}} \frac{\partial^{4} H}{\partial R^{4}} \cdot H+2 \frac{1}{a^{2} b^{2}} \frac{\partial^{4} H}{\partial R^{2} \partial Q^{2}} \cdot H+\frac{1}{b^{4}} \frac{\partial^{4} H}{\partial Q^{4}} \cdot H+\frac{k H^{2}}{D}\right) \partial R \partial Q-a b \frac{q}{D} \int_{0}^{1} \int_{0}^{1} H \partial R \partial Q=0 .
$$

Re-writing Equation 31 gives

$$
W_{u v}=\frac{q \int_{0}^{1} \int_{0}^{1} H \partial R \partial Q}{D \int_{0}^{1} \int_{0}^{1}\left(\frac{1 \partial^{4} H}{a^{4} \partial R^{4}} \cdot H+2 \frac{1}{a^{2} b^{2} \partial R^{2} \partial Q^{2}} \cdot H+\frac{1 \partial^{4} H}{b^{4} \partial Q^{4}} \cdot H+\frac{k H^{2}}{D}\right) \partial R \partial Q}
$$

Introducing the integrands and substituting the boundary conditions as determined by Ogunjiofor [11], for SSSS plate on Winker foundation, the expression in equation (32) becomes. 


$$
W_{u v}=\frac{0.04 q}{D\left(0.2362 \frac{1}{a^{4}}+0.471836 \frac{1}{a^{2} b^{2}}+0.2362 \frac{1}{b^{4}}\right)+0.02390 k}
$$

\section{RESULTS AND DISCUSSIONS}

To check the validity of the model, a simply supported plate on elastic foundation solved by Zhong [4] using Reciprocal Theorem Method and Ling Xing [5] using General Exact Solution were considered. The same problem was analysed for an SSSS Rectangular plate on Winkler's foundation using COPs. The modulus of subgrade reactions is $50 \mathrm{MN} / \mathrm{m}^{2}$, the poison ratio of the soil is 0.35 , the thickness of the plate is $0.18 \mathrm{~m}$, the modulus of elasticity of the plate is $300 \mathrm{MN} / \mathrm{m}^{2}$, the dimensions of the plate are $\mathrm{a}=1 \mathrm{~m}$ and $\mathrm{b}=1 \mathrm{~m}$, the load is $1 \mathrm{~N} / \mathrm{m}^{2}$. The calculated results for six different locations are listed in Table-1.

Table-1: The deflections of SSSS rectangular plate on Elastic Foundation

\begin{tabular}{|l|l|l|l|l|l|l|}
\hline $\begin{array}{l}\text { Location } \\
(\mathbf{m})\end{array}$ & \multicolumn{3}{l}{ Deflections (10-8m) } & Percentage difference \\
\hline $\mathrm{X}$ & $\mathrm{y}$ & $\begin{array}{l}\text { [Zhong \& Fanjin, } \\
2012]\end{array}$ & $\begin{array}{l}\text { [Ling Xing \& Qu } \\
\text { Qing, 1997] }\end{array}$ & $\begin{array}{l}\text { [Present } \\
\text { Study] }\end{array}$ & $\begin{array}{l}\text { [Zhong \& Fanjin, } \\
2012]\end{array}$ & $\begin{array}{l}\text { [Ling Xing \& Qu } \\
\text { Qing, 1997] }\end{array}$ \\
\hline 0.5 & 0.5 & 0.585 & 0.591 & 0.579 & 1.025641 & 2.030457 \\
\hline 0.5 & 0.4 & 0.577 & 0.583 & 0.578 & -0.17331 & 0.857633 \\
\hline 0.5 & 0.3 & 0.555 & 0.559 & 0.564 & -1.62162 & -0.89445 \\
\hline 0.5 & 0.2 & 0.521 & 0.523 & 0.500 & 4.03071 & 4.397706 \\
\hline 0.5 & 0.1 & 0.494 & 0.494 & 0.0492 & 0.404858 & 0.404858 \\
\hline 0.5 & 0.0 & 0.478 & 0.473 & 0.0462 & 3.34728 & 2.325581 \\
\hline
\end{tabular}

From the comparison of the results in Table-1, it can be seen that the results obtained by using this method are quite close to the results obtained in other studies. It would be noticed also that the plate deflections decreases as the location of the load is moved towards the end supports.

It is seen that the approach is very good for analysis of rectangular plate on elastic foundation. Only simple definite integration is needed to obtain a solution for this problem. It is a known shortcoming of solution of some methods that is not possible to select shape functions which exactly satisfy the simple edge conditions. The problem is completely eliminated here. The mathematical technique described here is applicable to other complicated problems, such as point-supported plates etc.

\section{CONCLUSIONS}

In this study, a simply supported rectangular plate resting on Winkler's foundation was analysed using COPs. The characteristic orthogonal polynomials derived shape functions for SSSS plate is satisfactory in obtaining a solution for this problem and the governing differential equation can be satisfied throughout the domain of the plate.

Therefore, an energy approach (based on Galerkin's method) could be used in confidence to satisfactorily analyse real time rectangular thin plate on elastic foundation of various boundary conditions under uniformly distributed loading and other loading conditions.

\section{REFERENCES}

1. Timoshenko, S. P., \& Woinowsky-Krieger, S. (1959). Theory of Plates and shells (2 ${ }^{\text {nd }}$ Ed.). Auckland: McGraw-Hill Inc.

2. Karasin, A. (2004) "an improved finite civil solution for plates on generalized foundations, Ph.D. Thesis submitted to post graduates school of natural and applied sciences of the middle east technical university.

3. Ragesh, P. P., Mustafa, V., Somasundaran, T. P. (2014). An integrated Kirchhoff plate element by Galerkin method for the analysis of plates on elastic foundations, IOSR, Journal of Mechanical and Civil Engineering. Special Issue, 2014, 20-24

4. Zhong, Y., Gao, Y., \& Fanjin, B. (2012). Solution for a rectangular plate on elastic foundation with free edges, using reciprocal theorem method, Mathematician Aeterna, 2:335-343.

5. Ling, X. F., \& Qu Q. Z. (1997). General Exact Solution of orthogonal rectangular plate with four free edges rested on elastic foundation, Journal of structure China (in Chinese), 31:491-498.

6. Chakraverty, S. (2009). Development of characteristic orthogonal polynomials (Cops): In Vibration Problems Vibration of Plates. Boca Raton: CRC Press Conference.

7. Bhat, R. B. (1985). Natural frequencies of rectangular plates using characteristic orthogonal polynomials in rayleigh-ritz method. Journal of sound and vibration, 102(4):493-499.

8. Brown, R. E., \& Stone, M. A. (1997). On the use of polynomial series with the Rayleigh Ritz method. Composite Structures, 39(3-4):191-196.

9. Ezeh, J. C., Ibearugbulem, M. O., Opara H. E., \& Oguaghamba, O. A. (2014). Characteristic orthogonal polynomial, application to galerkin 
indirect variational method for simply supported plate under in plane loading. Journal of Research in Engineering and Technology, 3(4):720-725.

10. Ibearugbulem, O. M., Ezeh, J. C., \& Ettu, L. O. (2014). "Energy methods in theory of rectangular plates (use of polynomial shape functions), (1st edition). Liu House of Excellence Ventures Publishers Owerri, Nigeria.

11. Ogunjiofor E. I. (2017). "Analysis of rectangular plate on winkler foundation using characteristics orthogonal polynomials". Masters Thesis submitted to Postgraduate school, University of Nigeria, Nsukka, Nigeria. 